\title{
Turnover Intention Ditinjau dari Workplace Bullying, Workplace Spirituality, dan Self- Esteem
}

\author{
Nur Farah Fitriyani \\ Liany Luzvinda, M.Si \\ Fakultas Psikologi UIN Syarif Hidayatullah Jakarta \\ farah.nurfitriyani@gmail.com, liany.luzvinda@uinjkt.ac.id
}

\begin{abstract}
The purpose of this study is to find out what variables affect employees who tend to leave or stay in the company. In this study predicted workplace bullying, workplace spirituality and self esteem, affect employee turnover. Subjects in the study were 206 stewardesses who were obtained by accidental sampling technique. Test the validity of measuring instruments using confirmatory factor analysis (CFA) techniques. Data analysis uses multiple regression analysis techniques. The results showed that there was a significant effect of workplace bullying, workplace spirituality and self-esteem on turnover intention. Minor hypothesis test results show that inner life and meaning and purpose in work significantly affect turnover intention. In contrast, work-related bullying, person-related bullying, physical bullying, and self-esteem are not significant in influencing turnover intention.
\end{abstract}

Keyword: Turnover intention, workplace bullying, workplace spirituality, self-esteem

\begin{abstract}
Abstrak
Tujuan penelitian ini adalah untuk mengetahui variabel apa saja yang mempengaruhi karyawan cenderung memilih keluar (turnover) atau bertahan dalam perusahaan. Dalam penelitian ini diprediksi workplace bullying, spiritualitas ditempat kerja dan self-esteem, berpengaruh terhadap turnover karyawan. Subyek pada penelitian berjumlah 206 pramugari yang diperoleh dengan teknik accidental sampling. Uji validitas alat ukur menggunakan teknik confirmatory factor analysis (CFA). Analisis data menggunakan teknik analisis regresi berganda. Hasil penelitian menunjukan bahwa ada pengaruh yang signifikan workplace bullying, workplace spirituality, dan self-esteem terhadap turnover intention. Hasil uji hipotesis minor menunjukkan bahwa inner life dan meaning and purpose in work secara signifikan mempengaruhi turnover intention. Sebaliknya, work-related bullying, person-related bullying, physical bullying, dan self-esteem tidak signifikan dalam mempengaruhi turnover intention.
\end{abstract}

Kata Kunci: Turnover intention, workplace bullying, workplace spirituality, self-esteem 


\section{Pendahuluan}

Sumber Daya Manusia (SDM) merupakan aset terpenting dari perkembangan suatu perusahaan maupun organisasi. Hal ini mendorong suatu perusahaan menyadari bahwa SDM merupakan salah satu nilai investasi yang penting bagi perusahaan. Perusahaan saling bersaing untuk mencari tenaga kerja yang memiliki keahlian dan kemampuan yang berkualitas. Permasalahan yang dihadapi oleh perusahaan dalam hal ini adalah tidak hanya mencari, perusahaan juga perlu mempertahankan dalam artian mencegah karyawan untuk keluar dari perusahaan terutama karyawan-karyawan yang sudah memiliki kriteria untuk memajukan organisasi. Hal ini disebabkan karena energi dan waktu yang dikhususkan untuk menemukan karyawan baru yang sesuai dengan kriteria. Selain itu, waktu yang dibutuhkan untuk mencari karyawan baru agar dapat mencapai tingkat maksimum produktivitas terkadang dapat menghambat organisasi dalam mencapai tujuan (Waldman, Kelly, Arora, \& Smith, 2004). Hal ini sejalan dengan apa yang dikemukakan oleh Staw, Darmon, Hom dan Griffeth (Ton \& Huckman, 2008) bahwa turnover memiliki efek negatif secara langsung seperti biaya pesangon dan perekrutan serta pengadaan pelatihan karyawan baru. Perusahaan berinvestasi banyak pada karyawan mereka, seperti saat pengenalan dan pelatihan, pengembangan, memelihara dan mempertahankan karyawan dalam perusahaan. Perusahaan harus mengeluarkan biaya yang cukup tinggi dan waktu untuk mencari sumber daya manusia yang kompeten untuk mengisi jabatan yang kosong serta memberikan pelatihan bagi karyawan baru (Ongori, 2007).

Dari hasil penelusuran workplace bullying memberikan sumbangan terbesar terhadap turnover karyawan. Menurut Alwis (2015) workplace bullying merupakan salah satu masalah besar hampir di berbagai jenis organisasi. Workpace bullying merupakan salah satu penyebab utama karyawan ingin meninggalkan organisasi. Oleh karena itu, workplace bullying merupakan salah satu masalah organisasi yang paling penting untuk diselesaikan. Berdasarkan penelitian yang dilakukan oleh Jaya surya menunjukkan ada dua hal yang mungkin dilakukan oleh karyawan yang merasa dirinya mendapatkan bullying, diataranya adalah meninggalkan perusahaan atau mengalahkan pelaku yang melakukan intimidasi. Namun banyak organisasi yang tidak mengungkapkan kasus bullying yang terjadi di dalam organisasi. Organisasi tersebut menyimpan rahasia tersebut. Menurut Askew (2013), workplace bullying merupakan keterlibatan berulang dan sistematis dari perilaku pelecehan interpersonal yang secara negatif dapat mempengaruhi baik individu yang ditargetkan maupun organisasi kerja dalam hal ini adalah turnover. Hal ini merupakan salah satu alasan urgensi untuk membahas kasus workplace bullying sehingga tidak ada lagi pihak yang dirugikan yang disebabkan oleh bullying.

Berdasarkan hasil penelitian yang lakukan pada awak kabin penerbangan dari tahun 1999-2013 menunjukan tingkat turnover mencapai $11 \%$ pertahun. Data yang diperoleh, pramugari menunjukkan angka tahunan turnover yang lebih tinggi dibandingkan dengan pramugara, dengan rata-rata presentase sebesar $15 \%$ pramugari dan 9,7\% pramugara (Shehada, 2015). Pada saat bertugas, pramugari menghadapi situasi konflik diantaranya adalah menghadapi keluhan maupun sikap yang kurang menyenangkan dari penumpang menenangkan penumpang saat terjadi cuaca buruk., (Basmallah, 2016), tekanan dari senior dan rekan kerja (Desyana, 2012). Kondisi-kondisi ini dapat memunculkan keinginan untuk keluar dari pekerjaan. 
Bullying ditempat kerja dapat mempengaruhi karyawan baik fisik maupun psikologis. Bullying dapat merusak hubungan sehat antar karyawan dan pada akhirnya karyawan memutuskan untuk meninggalkan perusahaan. Oleh karena itu, manager seharusnya menciptakan budaya yang kondusif bagi organisasi dalam hal ini adalah spiritualitas di tempat kerja. Pada penelitian terdahulu, penelitian yang mengkaitkan bullying terhadap turnover karyawan sudah cukup banyak. Namun masih jarang penelitian yang memasukkan variabel spiritualitas kerja didalamnya.

Spiritualitas kerja juga dikenal dengan istilah workplace spirituality. Workplace spirituality merupakan budaya dimana nilai-nilai organisasi mendorong rasa tujuan melalui pekerjaan yang bermakna yang terjadi dalam konteks komunitas tempat kerja (Giacalone dan Jurkiewicz, 2010). Peneliti menemukan bahwa workplace spirituality dan intensi turnover berkorelasi negatif, dengan peningkatan level workplace spirituality yang mengakibatkan berkurangnya turnover karyawan (Crawford et al. 2009). Seperti halnya penelitian yang dilakukan oleh Kumar, Ramendran, dan Yacob (2012), turnover intention dipengaruhi oleh organizational culture. Kultur organisasi dapat menjadi penentu apakah seseorang dapat bertahan atau tidak di perusahaan. Salah satu kultur organisasi yaitu perilaku workplace bullying dimana perilaku workplace bullying memberikan pengaruh cukup besar terhadap turnover intention. Bersadarkan penelitian yang dilakukan oleh Glambek, Matthiesen, Hetland, dan Einarsen (2014) menunjukan bahwa workplace bullying memberikan sumbangan sebanyak 40,6\% terhadap turnover intention pekerja laut Utara. Pada tahun 2007, Workplace Bullying Institute (Atkins, 2008) melaporkan bahwa 77\% kasus bullying diselesaikan ketika korban meninggalkan organisasi.

Turnover terjadi karena ketidaknyamanan terhadap tempat kerja. Salah satu penyebab karyawan tidak nyaman dengan pekerjaannya karena pekerjaan tersebut, bisa disebabkan karena karyawan tidak menemukan makna dalam pekerjaannya dalam hal ini adalah workplace spirituality. Apabila spiritualitas dikembangkan ditempat kerja, maka kebutuhan yang paling mendalam dalam diri karyawan terpenuhi, dan meningkatkan harmoni di lingkungan kerja. Menurut McCormic (1994), pada saat ini sudah semakin banyak perusahaan yang menggabungkan antara spiritualitas dan manajemen. Workplace spirituality dapat mempengaruhi misi dan tujuan organisasi serta dapat menjadi fondasi karyawan dalam berpikir, bertingkah laku, dan mengambil keputusan (Milliman, Ferguson, Trickett, \& Condemi, 1999). Perusahaan Southwest Airlines diketahui sebagai salah satu perusahaan yang memiliki nilai spiritualitas di tempat kerja yang tinggi dan menunjukkan turnover karyawan yang paling rendah $(6 \%)$ di dunia industri penerbangan (

Milliman, et al 1999). Karyawan yang memiliki spiritualitas di tempat kerja akan dapat menyatukan dirinya dengan tujuan organisasi, sehingga ketika ia merasakan kondisi kerja yang nyaman maka ia akan memilih untuk tetap tinggal pada perusahaan. Oleh karena itu, penelitian ini menggunakan variabel workplace spirituality sebagai variabel kedua yang mempengaruhi turnover intention pada pramugari.

Karyawan yang memiliki workplace spirituality, akan memaknai pekerjaan sebagai bagian dari kehidupan pribadi yang berada dalam konteks sosial (Ashmos \& Duchon, 2000). Hasil penelitian Hong (2000) memperkuat hasil penelitian sebelumnya bahwa workplace spirituality memberikan pengaruh negatif yang signifikan terhadap turnover intention. Hal ini berarti, apabila karyawan memiliki workplace spirituality yang tinggi maka karyawan tersebut akan cenderung untuk tetap berada dalam organisasi. 
Berdasarkan penelusuran penelitian sebelumnya, selain workplace spirituality, kepribadian dapat menjelaskan variasi dalam turnover. Kepribadian meliputi faktor biologis, sosial, dan kognitif yang menjadikan setiap orang berbeda, hal ini mempengaruhi individu itu sendiri dan perilaku organisasi (Jeswani \& Dave, 2012). Sehubungan dengan hal tersebut, menurut Barrick dan Mount (2005) bahwa kepribadian telah menjadi prediktor terbaik dari perilaku organisasi dan para peneliti telah menemukan kepribadian berkaitan dengan banyak perilaku organisasi diantaranya adalah turnover.

Menurut Pierce (Rizwan \& Sajid, 2014) self-esteem adalah level dimana individu yakin dirinya kompeten, penting, dan mengagumkan sebagai bagian dalam organisasi. Pekerja yang memiliki self-esteem tinggi akan merasa dirinya dibutuhkan dan ingin tetap berada di dalam organisasi. Pierce dan Gardner (2004) menemukan bahwa individual self-esteem di tempat kerja memiliki peran yang signifikan dalam pembentukan sikap kerja, diantaranya adalah turnover intention. Rizwan dan Sajid (2014) menemukan bahwa self-esteem memiliki pengaruh negatif yang signifikan terhadap turnover intention. Pekerja yang merasa dirinya bagian dari organisasi secara emosional akan enggan untuk meninggalkan organisasi.

Penelitian yang dilakukan oleh Lee (2013) juga menunjukkan bahwa self-esteem mempengaruhi turnover intention secara signifikan, dan hubungan antara keduanya adalah negatif. Kriteria bekerja sebagai seorang Pramugari dituntut untuk memiliki rasa percaya diri yang tinggi. Albert (2006) juga berpendapat bahwa Pramugari dengan self-esteem yang tinggi akan memiliki dasar yang baik dalam menjalin hubungannya dengan pekerjaannya, terutama pada saat menghadapi penumpang. Selfesteem yang tinggi tersebut diperlukan juga ketika menghadapi situasi darurat di dalam pesawat. Berdasarkan paparan diatas, oleh karena itu perlu dilakukan penelitian berkenaan dengan pengaruh workplace bullying, workplace spirituality, dan self-esteem terhadap turnover intention.

\section{Hipotesis}

Dalam penelitian ini, peneliti ingin melihat apakah tingkat turnover intention yang merupakan variabel dependen, bergantung pada tinggi rendahnya skor pada variabel independen yang ditetapkan dalam penelitian ini yaitu workplace bullying, workplace spirituality, dan self-esteem. Adapun hipotesis dalam penelitian ini adalah sebagai berikut:

$\mathbf{H}_{\mathbf{1}}$ : Ada pengaruh yang signifikan antara workplace bullying (work-related bullying, person-related bullying, dan physical bullying), workplace spirituality (inner life, meaning and purpose in work, dan sense of connection and community) dan self-esteem terhadap turnover intention pada Pramugari maskapai X.

Adapun rincian hipotesis dari masing- masing variabel independen terhadap variabel dependen:

$\mathbf{H}_{2}$ : Ada pengaruh yang signifikan work-related bullying pada workplace bullying terhadap turnover intention

$\mathbf{H}_{3}$ : Ada pengaruh yang signifikan person-related bullying pada workplace bullying terhadap turnover intention

$\mathbf{H}_{4}$ : Ada pengaruh yang signifikan physical bullying pada workplace bullying terhadap turnover intention 
H$_{5}$ : Ada pengaruh yang signifikan inner life pada workplace spirituality terhadap turnover intention $\mathbf{H}_{6}$ : Ada pengaruh yang signifikan meaning and purpose in work pada workplace spirituality terhadap turnover intention

$\mathbf{H}_{7}$ : Ada pengaruh yang signifikan sense of connection and community pada workplace spirituality terhadap turnover intention

$\mathbf{H}_{\mathbf{8}}$ : Ada pengaruh yang signifikan self-esteem terhadap turnover intention

\section{Metode Penelitian}

Penelitian ini menggunakan pendekatan kuantitatif dengan analisis multiple regression. Populasi dalam penelitian ini adalah pramugari Maskapai X. Jumlah sampel pada penelitian ini berjumlah 206 orang. Pengambilan sampel pada penelitian ini menggunakan teknik non-probability sampling.

Alat ukur yang digunakan untuk mengukur turnover intention yaitu alat ukur yang dibuat oleh Mobley, Horner, dan Hollingsworth (1978). Terdiri dari tiga item dan peneliti menambahkan dua item. Kemudian untuk mengukur workplace bullying menggunakan skala Negative Act Questionnaire (NAQ) dari Einarsen (2005). Skala workplace spirituality dalam penelitian ini adalah Workplace Spirituality Scale oleh Ashmos dan Duchon (2000). Pengukuran self-esteem menggunakan Rosenberg Self-esteem Scale (RSIS) yang dibuat oleh Rosenberg.

Dalam rangka menguji hipotesis penelitian, penulis menggunakan analisis regresi berganda. Dalam hal ini yang dijadikan DV (variabel yang dianalisis variannya) adalah turnover intention, sedangkan yang dijadikan IV (prediktor) adalah workplace bullying, workplace spirituality, dan self-esteem.

Adapun persamaan regresi berganda untuk penelitian ini adalah sebagai berikut:

$Y^{\prime}=a+b_{1} X_{1}+b_{2} X_{2}+b_{3} X_{3}+b_{4} X_{4}+b_{5} X_{5}+b_{6} X_{6}+b_{7} X_{7}+b_{8} X_{8}+e$

Keterangan :

$\mathrm{Y}^{\prime} \quad=$ Nilai prediksi Y (turnover intention)

$\mathrm{a} \quad=$ Intercept (konstan)

$\mathrm{b}=$ Koefisien regresi untuk masing-masing $\mathrm{X}$

$\mathrm{X}_{1} \quad=$ Work-related bullying

$\mathrm{X}_{2} \quad=$ Person-related bullying

$\mathrm{X}_{3} \quad=$ Physical bullying

$\mathrm{X}_{4}=$ Inner life

$\mathrm{X}_{5} \quad=$ Meaning and purpose in work

$\mathrm{X}_{6} \quad=$ Sense of connection and community

$\mathrm{X}_{7} \quad=$ Self-esteem

$e \quad=$ Residu 


\section{Hasil Penelitian}

Pada tabel 1 dapat dilihat bahwa diperoleh $R$-Square sebesar 0.382., artinya proporsi varian dari turnover intention yang dijelaskan oleh workplace bullying (work-related bullying, person-related bullying, dan physical bullying), workplace spirituality (inner life, meaning and purpose in work, dan sense of connection and community) dan self-esteem adalah sebesar 38,2\%.

\section{Tabel 1}

R square

\begin{tabular}{ccccc}
\hline Model & $\mathrm{R}$ & $\mathrm{R}$ Square & Adjusted R Square & Std. Error of the Estimate \\
\hline 1 & .618 & .382 & .360 & 7.54346 \\
\hline
\end{tabular}

Langkah kedua peneliti menguji apakah seluruh independen variabel memiliki pengaruh yang signifikan terhadap turnover intention. Adapun hasil uji F dapat dilihat pada tabel 2.

\section{Tabel 2}

Anova pengaruh seluruh IV terhadap DV

\begin{tabular}{ccccccc}
\hline & Model & Sum of Squares & Df & Mean Square & F & Sig. \\
\cline { 1 - 4 } 1 & Regression & 6971.426 & 7 & 995.918 & 17.502 & $.000^{\mathrm{b}}$ \\
& Residual & 11266.945 & 198 & 56.904 & & \\
& Total & 18238.371 & 205 & & & \\
\hline
\end{tabular}

Berdasarkan uji $\mathrm{F}$ pada tabel 3, dapat dilihat bahwa nilai $\mathrm{p}$ (Sig.) pada kolom paling kanan adalah $\mathrm{p}=0.000$ dengan nilai $\mathrm{p}<0.05$. Dengan demikian hipotesis nihil yang berbunyi "tidak ada pengaruh workplace bullying, workplace spirituality, dan self-esteem terhadap turnover intention, ditolak". Hal ini berarti, ada pengaruh yang signifikan workplace bullying (work-related bullying, personrelated bullying, dan physical bullying), workplace spirituality (inner life, meaning and purpose in work, dan sense of connection and community), dan self-esteem terhadap turnover intention. Langkah selanjutnya, peneliti melihat koefisien regresi dari masing-masing independent variable.

Jika Sig. <0,05 maka koefisien regresi tersebut signifikan yang berarti variabel independen tersebut memiliki pengaruh yang signifikan terhadap turnover intention. Adapun besarnya koefisien regresi dari masing-masing variabel independen terhadap turnover intention dapat dilihat pada tabel 3. 


\section{Tabel 3}

\section{Koefisien Regresi}

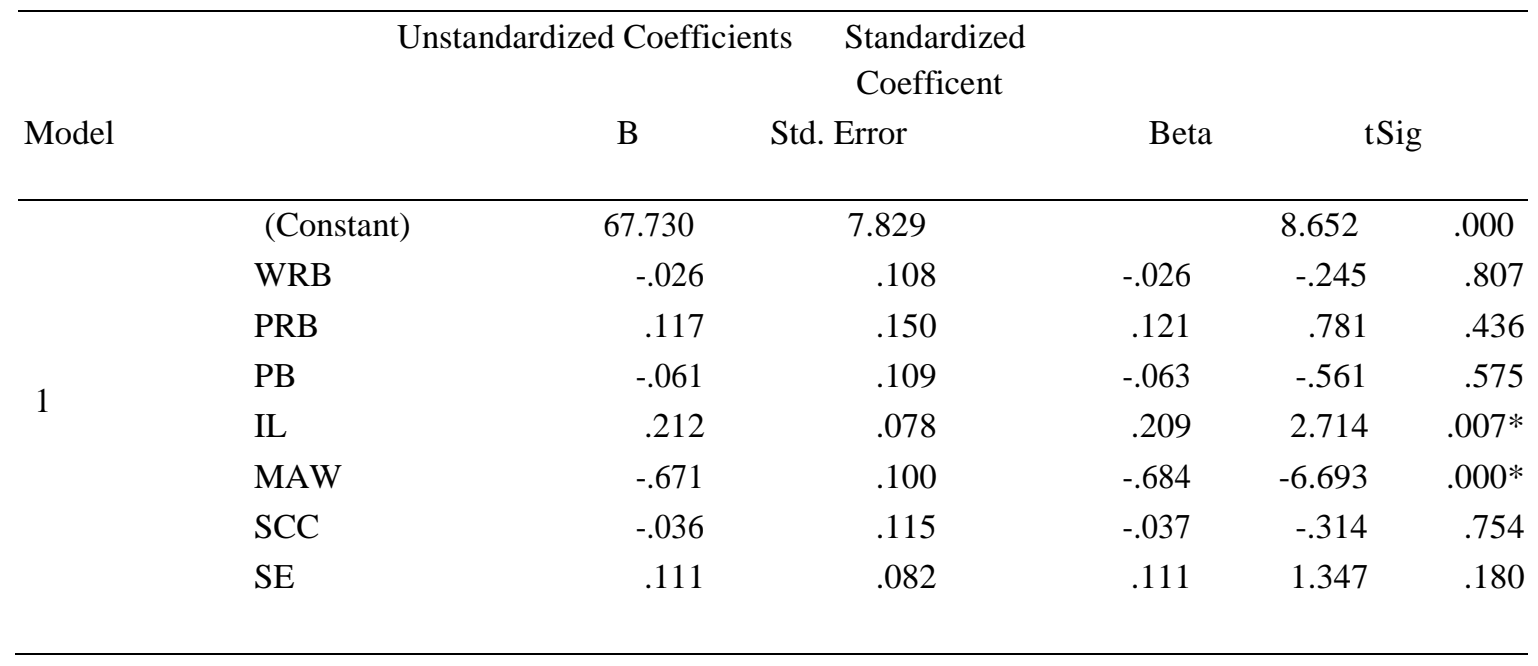

Berdasarkan koefisien regresi pada tabel 3, maka persamaan regresinya sebagai berikut: (*signifikan)

Turnover intention $=67,730-0,026$ work-related bullying $+0,117$ person-related bullying 0.061 physical bullying $+0,212$ inner life ${ }^{*}-0,671$ meaning and purpose in work ${ }^{*}-0.036$ sense of connection and community +0.111 self-esteem

Dari persamaan regresi tersebut, dapat diketahui bahwa terdapat dua varibel yang nilai koefisien regresinya signifikan, yaitu; (1) inner life; (2) meaning and purpose in work.

\section{Diskusi}

Penelitian ini bertujuan untuk mengetahui faktor-faktor yang mempengaruhi terjadinya turnover intention di perusahaan. Faktor-faktor tersebut diantaranya ialah workplace bullying, workplace spirituality, dan self-esteem. Hasil penelitian menunjukkan bahwa terdapat pengaruh yang signifikan dari workplace spirituality (inner life dan meaning and purpose in work) terhadap turnover intention pramugari Maskapai X.

Hasil penelitian ini menunjukkan bahwa dimensi inner life merupakan dimensi dari workplace spirituality berpengaruh secara signifikan terhadap turnover intention. Nilai koefisien regresi menunjukan arah positif. Hal ini berarti bahwa semakin besar inner life yang dirasakan oleh seorang pramugari, maka semakin tinggi pula turnover intention pramugari yang dimunculkan. Penemuan ini merupakan penemuan baru yang berbeda dengan penelitian yang dilakukan oleh Hong (2000) yang menunjukan bahwa inner life berpengaruh negatif terhadap intention to leave pada pekerja medis.

Inner life merupakan pemahaman mengenai nilai-nilai mendasar yang dianut seseorang yang tercermin dalam perilakunya untuk kehidupan yang lebih memuaskan (Ashmos \& Duchon, 2000). Hal ini dapat dijelaskan bahwa, pada saat karyawan memiliki nilai penghayatan tentang spiritual yaitu yakin pada Tuhan, optimis terhadap harapan dalam hidup, memiliki nilai-nilai yang menjadi acuan dalam bertingkah laku, maka individu tersebut memiliki prinsip hidup yang tegas dengan 
berlandaskan nilai spiritualnya. Kondisi kerja yang bertentangan dengan kehidupan batinnya akan membuat individu tersebut memiliki keinginan untuk keluar dari perusahaan. Namun dari beberapa hasil penelitian sebelumnya menunjukkan spiritualitas di tempat kerja dapat menurun jika dikaitkan dengan agama. Hal ini disebabkan ada beberapa nilai agama yang tidak sesuai dengan nilai-nilai perusahaan. Seperti yang dikemukakan oleh Vaill (Duchon \& Plowman, 2005) bahwa kehidupan batin merupakan perasaan individu mengenai makna mendasar siapa mereka, apa yang mereka lakukan, dan kontribusi yang mereka buat.

Selain inner life, dimensi kedua dalam spirituality at work yaitu meaning and purpose in work juga memberikan pengaruh signifikan terhadap turnover intention pramugari. Nilai koefisien regresi menunjukkan arah negatif. Hal ini dapat dijelaskan bahwa semakin baik meaning and purpose in work yang dimiliki pramugari, maka akan semakin rendah turnover intention pramugari tersebut. Penelitian ini sesuai dengan penemuan Hong (2000) yaitu meaning and purpose in work mempengaruhi secara negatif turnover intention pada para pekerja medis. Seorang pramugari yang memaknai pekerjaannya dengan baik serta bekerja dengan sepenuh hati, maka ia akan mengganggap bahwa pekerjaannya merupakan hal yang penting dan berharga bagi dirinya. Sebagaimana pula yang diungkapkan oleh Sharma (2017) bahwa dengan adanya kebermaknaan dalam bekerja, maka seseorang akan memiliki tujuan yang kuat dalam bekerja sehingga individu bersemangat dan menikmati pekerjaanya. Keyakinan tersebut akan membuat individu merasa enggan untuk meninggalkan perusahaan. Selain dengan memaknai pekerjaannya, pramugari menyadari tujuan dari pekerjaannya sehingga dapat memotivasi dirinya untuk tetap berada pada maskapai penerbangannya, sehingga keinginan keluar dari maskapainya rendah.

Dimensi sense of connection and community yang berasal dari variabel workplace spirituality dalam penelitian ini memberikan pengaruh yang tidak signifikan terhadap turnover intention. Saat seseorang merasa bahwa ia terhubung erat dengan rekan kerjanya maka akan menimbulkan rasa kekeluargaan yang erat sehingga akan membuat individu tersebut nyaman dan betah dengan pekerjaannya karena adanya dukungan sosial yang tinggi. Pada penelitian ini, tingginya rasa kebersamaan dan koneksi pramugari dengan rekan kerjanya tidak signifikan mempengaruhi turnover bisa disebabkan karena adanya hal lain yang menjadi prioritas dirinya dalam bekerja, sehingga rasa kebersamaan dan keterhubungan dengan rekan kerja tidak menjadi faktor tinggi rendahnya keinginan untuk keluar dari maskapai.

Variabel independen lainnya menghasilkan koefisien regresi yang tidak signifikan yaitu, workrelated bullying, person-related bullying, dan physical bullying, ketiga variabel tersebut merupakan variabel workplace bullying. Subjek pada penelitian ini merupakan pramugari, dimana untuk menjadi seorang pramugari dibutuhkan persaingan yang ketat dan saat menjalani pelatihan, mereka dilatih untuk menjadi pribadi yang kuat dan tangguh. Mental yang kuat dan tangguh tersebut dapat menyebabkan workplace bullying tidak berpengaruh secara signifikan terhadap turnover intention pada pramugari.

Variabel self-esteem dalam penelitian ini memberikan pengaruh yang tidak signifikan. Calon pramugari dilatih sebelum bertugas di dalam pesawat sehingga mereka memiliki kepercayaan diri yang tinggi, tenang dalam menghadapi situasi genting, dapat mengatasi penumpang yang bersikap tidak sopan, dan sebagainya. Hal tersebut dapat menjadi penyebab tidak signifikannya pengaruh self-esteem yang dimiliki pramugari terhadap turnover intention. 
Menambahkan variabel lain yang dapat mempengaruhi turnover intention seperti variabel yang mengukur spiritualitas organisasi, work-family conflict, resiliensi, dan self-efficacy. Hasil penelitian ini menunjukan variabel yang signifikan mempengaruhi turnover intention pramugari ialah inner life dan meaning and purpose in work. Pada penelitian lebih lanjut, disarankan untuk meneliti bagaimana cara meningkatkan inner life dan meaning and purpose in work pada karyawan terutama pada pramugari.

\section{Daftar Pustaka}

Albert, F. (2006). Psychological aspects of selection of flight attendants. Avation Mental Health: Psychological Implications For Air Transportation, 195-208.

Ashmos, D. \& Duchon, D. (2000). Spirituality at work: A conceptualization and measure. Journal of Management Inquiry, 9 (2), 134-145.

Askew, D. A., Schluter, P. J., \& Dick, M. L. (2013). Workplace bullying: What's it got to do with general practice?. Australian family physician, 42(4), 186.

Atkins, B. (2008). Workplace bullying an economic cancer in the american workplace. Thesis. Oakland: Department of Human Resource Development, Oakland University.

Barrick, M. (2005). Yes, personality matters: moving on to more important matters. Human Performance, 18(4), 359-372.

Basmallah, N. (2016). 14 Fakta mengejutkan profesi pramugari yang tak diketahui orang. Diunduh tanggal 17 Maret 2018 dari global.liputan6.com.

Crawford, A., S. S. Hubbard, S. R. Lonis-Shumate, and M. O’Neill. 2009. "Workplace Spirituality and Employee Attitudes within the Lodging Environment." Journal of Human Resources in Hospitality and Tourism 8: 64-81.

Jeswani, S. \& Dave, S. (2012). “Impact Of Individual Personality On Turnover Intention. A Study On faculty Members" : Management and Labour Studies, 37, (3), 253-265.

Desyana, C. (2012). Kata pramugari, pilot nyabu karena beban pekerjaan. Diunduh tanggal 30 Mei 2016 dari http://metro.tempo.co/read/news/2012/02/08/064382630/kata-pramugari-pilotnyabu-karena- beban-pekerjaan.

Alwis, De. C. A. (2015).’Workplace Bullying and Turnover Intention: A Study Of Moderators With Special Reference To Nurse.

Duchon, D., \& Plowman, D. A. (2005). Nurturing the spirit at work: Impact on work unit performance. The leadership quarterly, 16(5), 807-833.

Einarsen, S. (2005). The nature, causes and consequences of bullying at work: The Norwegian experience. Pistes, (7-3).

Giacalone, R. A., and C. J. Jurkiewicz. 2010. "The Science of Workplace Spirituality." In Handbook of Workplace Spirituality and Organizational Performance, edited by R. A. Giacalone and C. J. Jurkiewicz, 3-26, New York: M. E. Sharpe. 
Glambek, M., Matthiesen, S., Hetland, J., \& Einarsen, S. (2014). Workplace bullying as an antecedent to job insecurity and intention to leave: a 6-month prospective study. Human Resource Management Journal, 24(3), 255-268.

Hong, Young Joon. (2000). The Influence Of Perceived Workplace Spirituality On Job Satisfaction, Intention To Leave, And Emotional Exhaustion Among Community Mental Health Center Workers In The State Of Kansas. Seoul: Hankuk University of Foreign Studies.

Jeswani, S. \& Dave, S. (2012). Impact of individual personality on turnover intention: a study on faculty members. Management and Labour Studies, 37(3), 253-265.

Kumar, R., Ramendran, C., \& Yacob, P. (2012). A study on turnover intention in fast food industry: Employees' fit to the organizational culture and the important of their commitment. International Journal of Academic Research in Business and Social Sciences, 2 (5), 9-41.

Lee, J. (2013). Master of arts women in science, technology, engineering, and mathematics (stem) fields: The importance of the need to belong and self- esteem on the intention to leave a job. Thesis: San José State University.

Lee, Y., Lee, M., \& Bernstein, K. (2013). Effect of workplace bullying and job stress on turnover intention in hospital nurses. Diunduh tanggal 2 Maret 2016, http://synapse.koreamed.org/DO

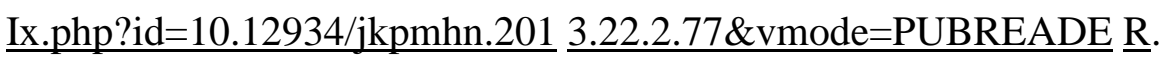

McCormick, D. W. (1994). Spirituality and management. Journal of Managerial Psychology, 9(6), 5-8. 